\title{
Performance comparison of artificial bee colony algorithm based approaches for retinal vessel segmentation
}

\author{
Mehmet Celalettin CIHAN", Mehmet Bahadır ÇETINKAYA ${ }^{2,}$, , Hakan DURAN ${ }^{3}$ \\ ${ }^{1}$ Kapadokya University, School of Health Sciences, Department of Audiology, Nevşehir \\ ${ }^{2,3}$ Erciyes University, Faculty of Engineering, Department of Mechatronics Engineering, Kayseri
}

Gelis Tarihi (Received Date): 16.10.2020

Kabul Tarihi (Accepted Date): 05.05.2021

\begin{abstract}
Structural changes in the retinal blood vessels provide important information about retinal diseases. Therefore, computer-aided segmentation of retinal blood vessels has become an active area of research in last decades. Due to the close contrast between the retinal blood vessels and the retinal background, robust methods should be developed to detect retinal blood vessels with high accuracy. In this work, artificial bee colony $(A B C)$ algorithm which provides effective solutions to engineering problems has been applied to the retinal vessel segmentation. Clustering based $A B C$ (basic $A B C$ ), quick- $A B C(Q-A B C)$ and modified $A B C(M R-A B C)$ algorithms have been analyzed for accurate segmentation of retinal blood vessels and their performances were compared. The simulations have been realized on the normal and abnormal retinal images taken from the DRIVE database. Simulation results and statistical analyses represent that $A B C$ based approaches are stable and able to reach to optimal clustering performance with higher convergence rates. As a result it can be concluded that $A B C$ based approaches can successfully be used for accurate segmentation of retinal blood vessels.
\end{abstract}

Keywords: Retinal blood vessel segmentation, artificial bee colony algorithm, quick artificial bee colony algorithm, modified artificial bee colony algorithm.

\footnotetext{
Mehmet Celalettin CïHAN, mcelalettincihan@gmail.com,http://orcid.org/0000-0003-3399-7188

*Mehmet Bahadır ÇETINKAYA, cetinkaya@erciyes.edu.tr, http://orcid.org/0000-0003-3378-4561

Hakan DURAN, hakanduran@erciyes.edu.tr, http://orcid.org/0000-0002-6696-6081
} 


\section{Retinal damar segmantasyonuna yönelik yapay arı koloni algoritması tabanlı yaklaşımların performans mukayesesi}

\section{$\ddot{\mathbf{O} z}$}

Retinal kan damarlarında meydana gelen yapısal değişiklikler retinal hastalıklara yönelik önemli bilgiler sağlamaktadır. Bu nedenle, son yillarda bilgisayar destekli retinal damar segmantasyonu uygulamaları önemli bir araştırma alanı haline gelmiştir. Retinal kan damarları ile retina görüntüsü art alanı arasındaki kontrast farkları çok düşük olduğu için retinal kan damarlarının yüksek doğrulukta tespit edilmesine yönelik güçlü algoritmalara ihtiyaç duyulmaktadır. Bu çalışmada, mühendislik problemlerine etkim çözümler üreten yapay arl koloni (ABC) algoritması retinal damar segmantasyonuna yönelik uygulanmıştır. Retinal kan damarlarının yüksek doğrulukta segmantasyonuna yönelik olarak kümeleme tabanl $A B C$ (temel $A B C)$, hızlı-ABC ( $Q$ $A B C)$ ve modifiye edilmiş $A B C(M R-A B C)$ algoritmalarl geliştirilmiş ve performanslarl mukayese edilmiştir. Benzetimler, DRIVE veri tabanından alınmış olan normal ve hastalıklı retinal görüntüler üzerinde gerçekleştirilmiştir. Benzetim sonuçları ve istatistiksel analizler ABC tabanlı yaklaşımların kararlı bir şekilde çalıştıklarını ve en uygun kümeleme performanslarına yüksek yakınsama hızlarında ulaştıklarını göstermektedir. Sonuç olarak, ABC tabanl yaklaşımların retinal kan damarlarının yüksek doğrulukta segmantasyonuna yönelik olarak başarılı bir şekilde kullanılabileceği görülmüştür.

Anahtar kelimeler: Retinal kan damar segmentasyonu, yapay arl koloni algoritmasl, hızl yapay arı koloni algoritması, modifiye edilmiş yapay arı koloni algoritması.

\section{Introduction}

Accurate detection and regular follow up of the changes occurring in the retinal blood vessels are too important to early diagnosis and correct treatment. Structural changes in the retinal blood vessels are precursors of serious retinal diseases such as diabetic retinopathy, hypertension, arteriosclerosis and cardiovascular diseases [1-3]. Retinal blood vessel segmentation can be defined as the detection of changes occurring in the retinal blood vessels and it also gives knowledge about the location of the retinal blood vessels $[4,5]$.

Due to the complexity of information obtained after retinal blood vessel, segmentation, manual measurements cannot produce accurate results enough. Therefore, computeraided methods should be used to perform an accurate retinal blood vessel segmentation. In literature the most common used methods for retinal blood vessel segmentation can be classified as kernel-based, tracking-based and classifier based methods.

Kernel-based methods in which the whole retinal image is being filtered by using a vessel like kernel include morphological methodology [6-8] and matched filters [9-13]. In morphological methodology, the retinal blood vessels are highlighted with approaches such as top-hat and bottom-hat [8]. In the matched filter methodology, in order to detect the retinal blood vessels the matched filter structures such as Gaussian type filters [9-13] and Wavelet filters [14] are being used. Kernel-based methods have 
two main disadvantages. Firstly, the matched filters may usually detect undesired regions such as bright blobs. Secondly, in this method additional kernels needed to be used to detect vessels with different thicknesses at different orientations.

The basic philosophy of tracking-based methods is edge detection. The vessels attempted to be detected by using edge information. Tracking-based methods use various vessel profile models such as Gaussian profile [15], generic parametric model [16], Bayesian probabilistic model [17] and multi-scale profile [18] to obtain the best matching model. The most important disadvantage of these methods is that the bifurcations at the edges of the vessels cannot be accurately detected in thin vessels.

The classifier based methods can be grouped as supervised and unsupervised methods. Supervised methods [19-21,22,23] use some prior information belonging to the relevant vessel to associate a pixel as vessel or non-vessel pixel. In order to realize pixel classification the classifier based methods use different classifiers such as artificial neural network (ANN) [19-21], gaussian mixture model [23], K-nearest neighbour $(\mathrm{KNN})$ [22] and support vector machine (SVM) classifiers [23]. In contrast to supervised methods, the unsupervised methods do not need pre-classified data for retinal blood vessel segmentation [24, 25]. In general, the vessel segmentation performance of the classifier based methods is directly proportional to the feature of the pixels extracted from the retinal image. The feature extraction methods create feature vectors derived from the retinal image. In literature, the most common used methods while creating feature vectors are local binary patterns operator [20], a 7-D feature vector composed of gray level and moment invariants [21], Gabor wavelet transform [23], ridge detection [22], line operators [23], matched filters [24] and trench detection [25]. In addition to the methods mentioned above some researchers [26, 27] prefer to use methods based on eigenvalues and eigenvectors obtained from Hessian matrices. In this method, the elements of the Hessian matrices represent vesselness values and vessel directions. In [28], authors use a graph-based method to extract both vessel edges.

The conventional methods concluded above are well developed and frequently used in literature for clustering based retinal blood vessel segmentation. However, there are few works in literature including retinal image analysis by using heuristic algorithms. In contrast to conventional methods, heuristic algorithms can provide effective solutions to many engineering problems due to their flexible and robust structure. In this work, clustering based artificial bee colony, quick artificial bee colony and modified artificial bee colony algorithms have been applied for retinal blood vessel segmentation and then the performances of these approaches are compared. The analysis have been realized on the normal and abnormal retinal images taken from the Digital Retinal Images for Vessel Extraction (DRIVE) database. Figure 1 shows the normal and abnormal retinal images taken from DRIVE database. 


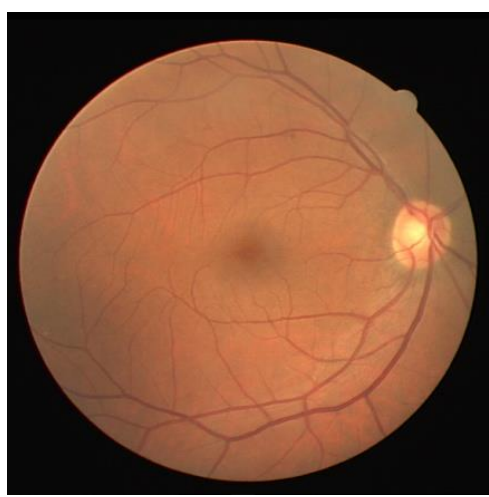

(a) Normal retinal image

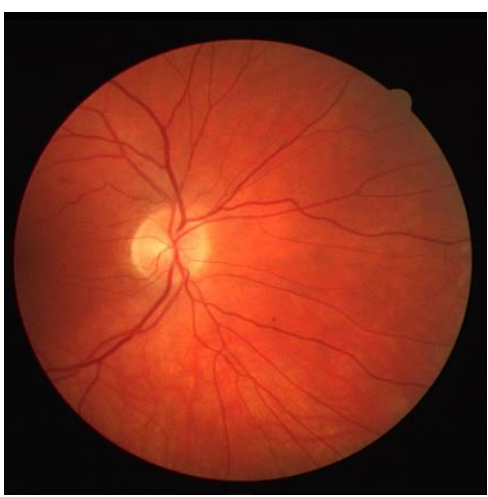

(b) Abnormal retinal image

Figure 1. Retinal images taken from DRIVE database.

The method proposed for retinal blood vessel segmentation includes two phases: preprocessing and artificial bee colony algorithm based segmentation. In order to improve the performance of retinal vessel segmentation, pre-processing operations have to be applied before clustering.

\section{Material and methods}

In order to increase the contrast between the vessels and the image background, as the first pre-processing application, the red (R), green $(\mathrm{G})$ and blue (B) layers of the retinal images of Figure 1 and Figure 2 were analyzed in terms of contrast and brightness. It was seen that the optimal contrast and brightness levels have been obtained in the Green (G) layer for both images due to the poor illuminance of R and B layers [29].

For this reason, after this step, the image analysis will be continued on the green layer in accordance with the literature [30]. The pre-processing mentioned above can be called as band selection. Despite the increase in contrast and brightness values of the retinal images after the pre-processing phase mentioned above, the contrast difference between the vessels and the image background was not found to be sufficient for a high clustering performance. Thus, a second pre-processing operation called bottom-hat transformation is applied in the next step to optimize the retinal image for clustering. This transformation can be described as extraction of the original image from the morphologically closed image. Bottom-hat filter removes the background of the image and only leaves dark areas which are smaller than the radius of the structural element used. Equation 1 represents the the enhancement obtained in the contrast between bright and dark areas after bottom-hat transformation,

bottom-hat $(g)=g-(g \bullet n B)$

where $g$ represents the mapping points taken from an Euclidean space in grayscale retinal image, $(\bullet)$ operatör determines the closing operation, $B$ is the grayscale structural element to be used, and $n$ is the bottom-hat transformation. In this work, a disk with $r=8$ pixel radius has been used as building element and bottom-hat transformation is applied as to be $n=8$. 
The green layer images obtained after band selection pre-processing for the retinal images taken from the DRIVE database given in Figures 1 (a) and (b), are given below with Figures 2 (b) and (e). This green layer images then subjected to bottom-hat transformation. The enhanced retinal images obtained after pre-processing operations have been represented in Figures 2 (c) and (f).

\subsection{Basic artificial bee colony algorithm $(A B C)$}

$\mathrm{ABC}$ algorithm which is proposed by Karaboga in 2005 [31] is one of the swarm intelligence based algorithms inspired from the collective behaviour of bees. In ABC algorithm, the colony includes employed bees, onlookers and scouts. In the models proposed in this work, half of the population consists of employed bees and the other half consists of onlookers. Employed bees are associated with randomly produced food source positions. The position of a food source represents a possible solution to the problem to be optimized and the nectar amount of a food source corresponds to the fitness (quality) value of the associated solution.

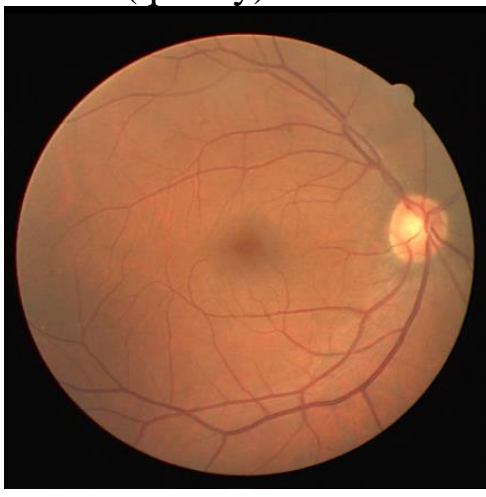

(a)

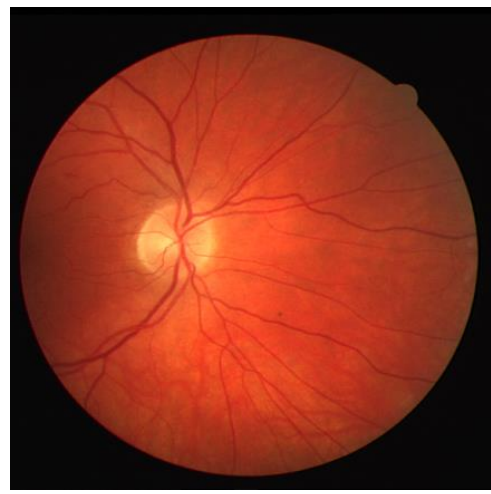

(d)

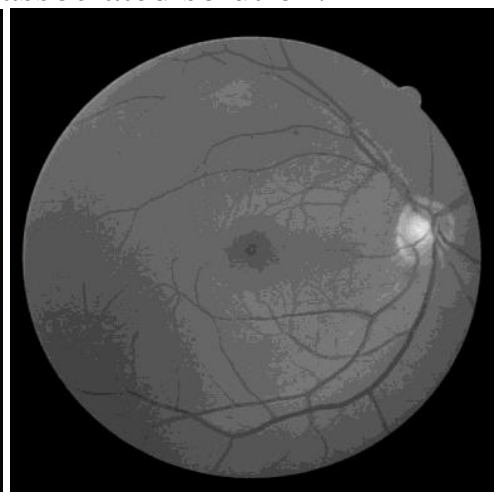

(b)

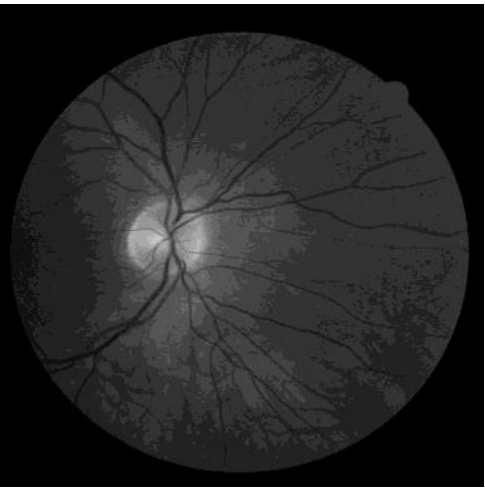

(e)

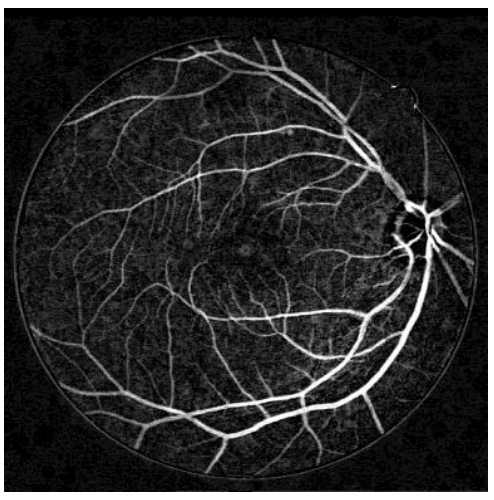

(c)

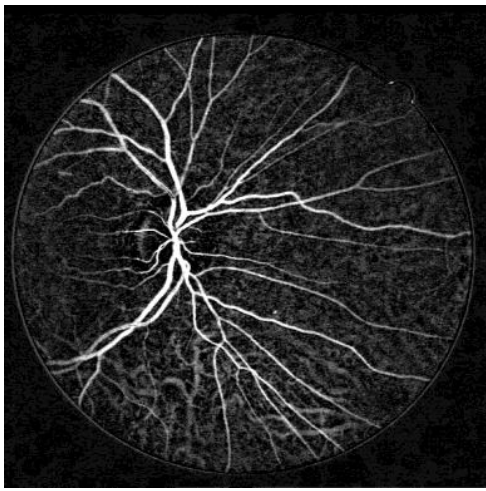

(f)

Figure 2. (a) and (d) are the normal and abnormal retinal images, (b) and (e) are the green layer images obtained as a result of band selection, (c) and (f) are the enhanced retinal images obtained after the bottom-hat filtering.

In $\mathrm{ABC}$ algorithm, the position of a food source represents a possible solution to the problem to be optimized and the nectar amount of a food source corresponds to the fitness (quality) value of the associated solution. Each employed bee shares its position info with onlooker bees by means of a dance performed into the hive. Onlooker bees select the food sources according to their fitness values. The last group is the scout bees. Scout bees search for previously undiscovered food sources regardless of any information. The initial phase of the search is carried out on randomly produced 
solutions. In further cycles, if a solution cannot be improved by a predetermined number of trials, the employed bee related to this solution becomes a scout. The number of trials for releasing a solution is controlled by an important control parameter called limit. The main loop of an $\mathrm{ABC}$ algorithm and the description of each phase are given below:

\author{
Initialization phase \\ REPEAT \\ Employed phase \\ Onlooker phase \\ Memorize the best solution achieved so far \\ Scout phase \\ UNTIL (termination criteria is met)
}

\title{
2.1.1. Initialization phase
}

In the initialization phase, an initial population is randomly created according to Equation 2.

$$
x_{m, i}=l_{i}+\operatorname{rand}(0,1) \cdot\left(u_{i}-l_{i}\right)
$$

where, $x_{m, i}$ represents the $i^{\text {th }}$ dimension of the $m^{\text {th }}$ solution. $u_{i}$ and $l_{i}$ are the upper and lower bounds of the $x_{m, i}$,respectively. An initial population consisting of randomly produced solutions can be shown as $P(c)=\left\{x_{m, i} \mid m=1,2, \ldots, S N\right\}$. Then, the fitness value of each initial solution is calculated by using Equation 3 and memorized.

$$
f i t\left(x_{m}\right)=\frac{1}{1+\left|f\left(x_{m}\right)\right|}
$$

\subsubsection{Employed phase}

In this phase, new possible neighbour solutions are determined within the neighborhood of the memorized solutions in the initialization phase. These new neighbour solutions can be obtained by using Equation 4 .

$$
v_{m, i}=x_{m, i}+\phi_{m, i}\left(x_{m, i}-x_{k, i}\right)
$$

where, $x_{k}$ is a randomly selected solution and $i$ determines the randomly selected dimension of $x_{k} . \phi_{m, i}$ is a coefficient that scales the new solution and it varies in the range of $[-1,1]$. After the new neighbour solution is produced, a greedy selection is applied between $x_{m}$ and $v_{m}$ according to their fitness values.

\subsubsection{Onlooker phase}

In onlooker phase, firstly, some of the solutions produced in employed phase are selected within a certain probability depending on their fitness values. The probability of a solution to be selected can be defined as the following, 


$$
p_{m}=\frac{f i t\left(x_{m}\right)}{\sum_{m=1}^{S N} f i t\left(x_{m}\right)}
$$

After this probabilistically selection process, as in the employed phase a neighbor solution $v_{m}$ is produced according to Equation 4. Then, the solution with higher fitness value is chosen by applying greedy selection between $x_{m}$ and $v_{m}$. Onlooker phase provides a positive feedback by ensuring that solutions with higher fitness value remain in the population.

\subsubsection{Scout phase}

The solution which cannot be improved despite "limit" number of trials can be thought as an exhausted solution. In Scout phase, the exhausted solutions are replaced with new solutions produced by using Equation 2. Thus, these new solutions produced in scout phase are transferred to the next generation instead of exhausted solutions.

\subsection{Quick artificial bee colony algorithm $(Q-A B C)$}

In basic $\mathrm{ABC}$, an onlooker chooses a food source depending on the information taken from the employed bee and then she directly evaluates only the corresponding source. This research methodology reduces the convergence rate because possible better solutions around the corresponding source are being ignored. To overcome this disadvantage of basic $\mathrm{ABC}, \mathrm{Q}-\mathrm{ABC}$ proposes a new search approach in onlooker phase [32]. In the proposed approach both the corresponding source and the new possible sources around it are evaluated and the solution with higher fitness value is selected. In this new model, the behaviour of onlookers can be modeled as the following,

$$
v_{N_{m}, i}^{\text {best }}=x_{N_{m}, i}^{\text {best }}+\phi_{m, i}\left(x_{N_{m}, i}^{\text {best }}-x_{k, i}\right)
$$

where, $x_{N_{m}}^{\text {best }}$ represents the best solution among the neighbours of $x_{m}$ and itself ( $N_{m}$ ). Namely, an onlooker memorizes the solution $x_{m}$ which transferred in employed phase and then she searches the region which is centered by $x_{m}$.

In Q-ABC algorithm, $x_{m}$ represents the possible solutions in the initial population which are produced by Equation 2. Firstly, the best solution around the $x_{m}$ itself is obtained and represented as $N_{m}$. In the next step, the best solution that occurs around the neighboring solutions of $x_{m}$ are obtained. Finally, the solution with higher fitness value among these two solutions is selected as the best solution. As a result of this search procedure, a regional search is performed instead of a local search.

In addition to the parameters of basic $\mathrm{ABC}$ algorithm, $\mathrm{Q}-\mathrm{ABC}$ has one more control parameter called neighbourhood radius $(r)$ which determines the radius of the search area around $x_{m}$. The value of $r$ parameter has to be chosen as, $\quad r \geq 0$ [32]. If $r$ is 
chosen as $r=0$, it is clear that $\mathrm{Q}-\mathrm{ABC}$ turns to be the standard $\mathrm{ABC}$, namely, $x_{N_{m}}^{\text {best }}$ will be equal to $x_{m}$.

\subsection{Modified artificial bee colony algorithm (MR-ABC)}

In basic $\mathrm{ABC}$, a possible solution in the neighbourhood of the present solution is being created by changing only one parameter of the present solution. This approach is restricting the radius of search space and as a result of this the convergence rate decreases especially in the initial phase of the search. To overcome this disadvantage of basic $\mathrm{ABC}$, the neighbor solution might be created by changing more than one parameter of the present solution. The $\mathrm{ABC}$ producing neighbour solutions in this way is called modified $\mathrm{ABC}$ [33]. In addition to the control parameters of basic $\mathrm{ABC}$, modified $\mathrm{ABC}$ has got one more control parameter called modification rate-MR. In modified $\mathrm{ABC}$ algorithm, the number of parameters to be changed while generating a neighbour solution is being determined according to MR parameter. The recommended value for this control parameter is between [0,1] [33].

Table 1 represents the control parameter values of the ABC based algorithms used.

Table 1. Control parameter values of the algorithms used in the simulations.

\begin{tabular}{|c|c|c|}
\hline ABC & Q-ABC & MR-ABC \\
\hline Maximum Cycle $=100$ & Maximum Cycle $=100$ & Maximum Cycle $=100$ \\
\hline Colony Size $=10$ & Colony Size $=10$ & Colony Size $=10$ \\
\hline Limit Value $=120$ & $\begin{array}{c}\text { Limit Value }=120 \\
\text { Radius }=1\end{array}$ & $\begin{array}{c}\text { Limit Value }=120 \\
\text { Modification Rate }=0.7\end{array}$ \\
\hline $\begin{array}{c}\mathrm{X}_{\max } \text { and } \mathrm{X}_{\min } \text { represent } \\
\text { the highest and lowest } \\
\text { pixel values of the image, } \\
\text { respectively. }\end{array}$ & $\begin{array}{c}\mathrm{X}_{\max } \text { and } \mathrm{X}_{\min } \text { represent the } \\
\text { highest and lowest pixel } \\
\text { values of the image, } \\
\text { respectively. }\end{array}$ & $\begin{array}{c}\mathrm{X}_{\max } \text { and } \mathrm{X}_{\min } \text { represent } \\
\text { the highest and lowest } \\
\text { pixel values of the } \\
\text { image, respectively. }\end{array}$ \\
\hline
\end{tabular}

\subsection{Retinal vessel segmentation}

As mentioned earlier the performances of the methods proposed in this work are evaluated on the retinal images taken from the DRIVE database which is the most used benchmark databases in retinal image analysis. DRIVE database [22] contains 40 color fundus photographs which were obtained by a diabetic retinopathy screening program. The screening population has been consisted of 453 subjects between 31 and 86 years of age. Each image has been JPEG compressed, which is common practice in screening programs. In this database, 7 of 40 images have pathology such as exudates, hemorrhages and pigment epithelium changes. The images have been captured by a Canon CR5 3 CCD camera with a $45^{\circ}$ field of view (FOV) and size is $700 \times 605$ pixels per color channel.

The flowchart of the retinal vessel segmentation process proposed in this work can be given as the following. 


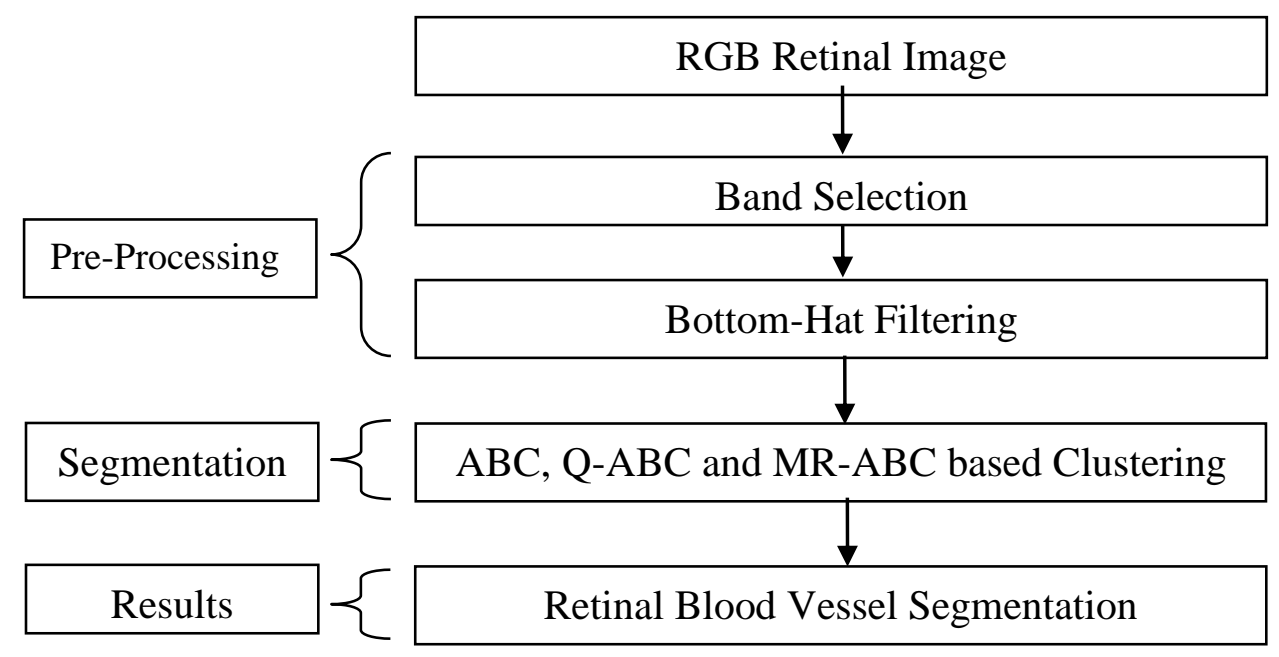

Figure 3. Flowchart of retinal vessel segmentation process.

When the R, G, and B layers of the RGB retinal image were analyzed, it was seen that the $G$ layer provides the highest contrast difference between the vessels and the background. Therefore, in the next steps analyses have been continued over the G layer. Although its higher rate of contrast, the $G$ layer is additionally subjected to preprocessing of bottom-hat filtering to be enhanced for a more successful clustering.

Retinal images enhanced and optimized for a successful clustering with pre-processing phase are then subjected to clustering based segmentation by the algorithms of ABC, Q$\mathrm{ABC}$ and MR-ABC. In the segmentation phase, optimal clustering centers have been determined by using $\mathrm{ABC}, \mathrm{Q}-\mathrm{ABC}$ and $\mathrm{MR}-\mathrm{ABC}$ algorithms in order to obtain the highest clustering performance and clustering has been realized according to these centers. In the clustering process cluster centers are randomly determined and all pixels are indexed to the closest cluster center. In order to measure the success of pixel indexing the Mean-Squared Error (MSE) criteria is used. The MSE function which determines the quality of the solutions can be expressed as the following,

$$
M S E=\frac{1}{N} \sum_{i=1}^{N}\left(f_{i}-y_{i}\right)^{2}
$$

As seen from the equation given above, MSE error function calculates the quality of a solution based on the distance between each pixel and its related cluster center. In this equation, $N$ represent the total number of pixels in the retinal image. Cluster centers are determined by algorithm and $f_{i}$ represents the value of the cluster center closest to the pixel $i$. Also, $y_{i}$ represents the pixel value of the $i^{\text {th }}$ pixel. The MSE error function allows the pixels to be grouped successfully around the appropriate cluster centers with minimum error.

\section{Simulation results}

Figure 4 represents the resulting retinal images obtained after applying segmentation to the images Figures 1 (a) and (b) by using the clustering based ABC, Q-ABC and MR- 
$\mathrm{ABC}$ algorithms. It is seen from the figures that some non-vessel regions with close pixel value to the real vessels have been segmented as vessel. Furthermore, factors such as low vessel contrast, irregular shaped lesions and vessels with low diameter reduce the clustering performance. Several post-processing approaches have been proposed to eliminate these regions. But in this work in order to represent the pure performance of the algorithms these post-processing methods have not been applied. It is clear from the figures that clustering based $\mathrm{ABC}, \mathrm{Q}-\mathrm{ABC}$ and $\mathrm{MR}-\mathrm{ABC}$ algorithms are able to cluster close pixel values at high accuracy.

\subsection{Performance measures}

The statistical performances of the algorithms are evaluated in terms of sensitivity (Se), specificity ( $\mathrm{Sp}$ ) and accuracy (Acc). The expressions of these statistical measures are given in Table 2.

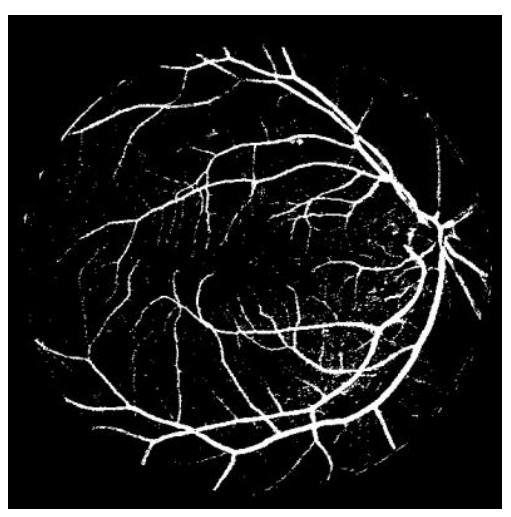

(a) $\mathrm{ABC}$

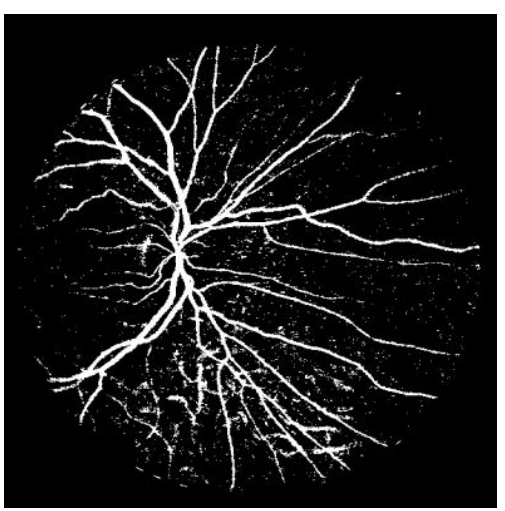

(d) $\mathrm{ABC}$

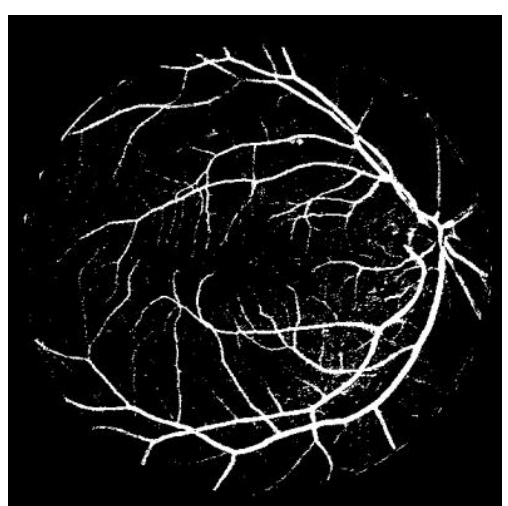

(b) Q-ABC

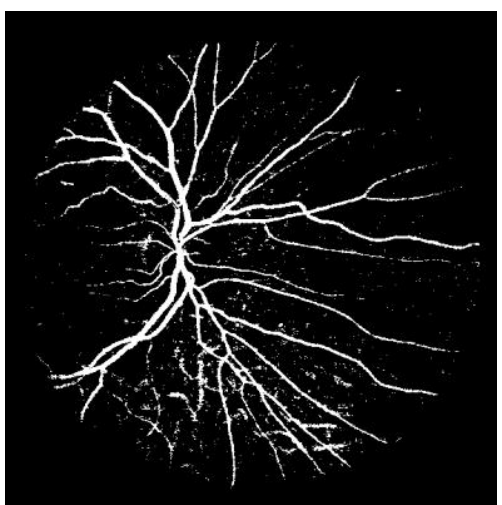

(e) Q-ABC

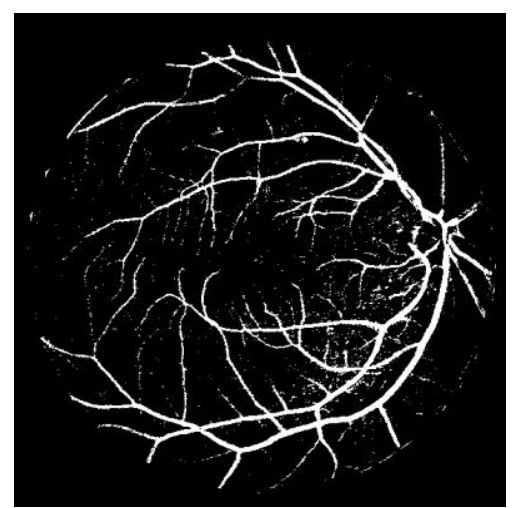

(c) MR-ABC

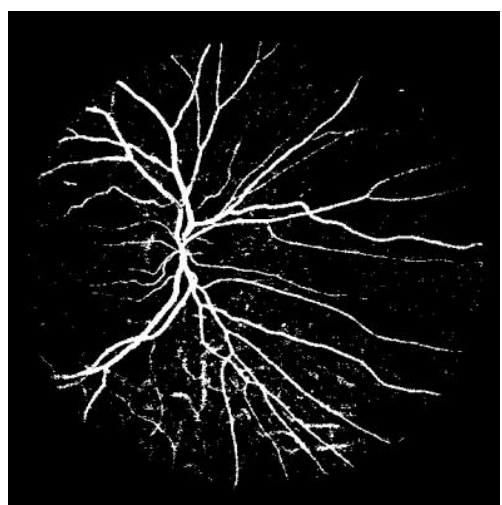

(f) MR-ABC

Figure 4. Retinal images obtained after applying segmentation to the images Figures 1 (a) and (b) by using the clustering based ABC, Q-ABC and MR-ABC algorithms.

Table 2. The expressions of the statistical measures used in the simulations.

\begin{tabular}{|c|c|}
\hline Measure & Description \\
\hline Se (Sensitivity) & $T P /(T P+F N)$ \\
\hline$S p($ Specificity) & $T N /(T N+F P)$ \\
\hline Acc (Accuracy) & $(T P+T N) /(T P+F N+T N+F P)$ \\
\hline
\end{tabular}


The true positive (TP) describes the number of correctly classified vessel pixels. The true negatives (TN) are the correctly classified background pixels and they can be considered as non-vessel pixels. The false positive (FP) represents the number of background pixels which are incorrectly classified as vessel pixels. The false negatives (FN) are the pixels which are actually vessel pixels but have been detected as background pixels. So the sensitivity $(\mathrm{Se})$ is the ratio of correctly classified vessel pixels while specificity $(\mathrm{Sp})$ is the ratio of correctly classified background pixels and accuracy (Acc) is the ratio of correctly classified both the vessels and background pixels.

\subsection{Performance analysis}

The simulations are realized on 20 retinal images taken from DRIVE database. The clustering performances of the algorithms are compared according to the statistical parameters of sensitivity, specificity and accuracy. The results obtained are given below with Table 3. From the results obtained for Se, it is seen that each algorithm is able to reach high performance in terms of the ratio of correctly classified vessel pixels. The $\mathrm{Sp}$ values reached represents that each algorithm can successfully distinguish the vessel pixels and background pixels. Finally, when the Acc values examined the results show that the ratio of correctly classified both the vessels and background pixels is very high for each algorithm. As seen from the results given in Table 3, although each algorithm produces similar results in terms of the mean values of the parameters, the MR-ABC has been performing the most successful clustering. In general, it can be said that the clustering performances of the $\mathrm{ABC}$ based algorithms are successful and close to each other.

Table 3. The performance measures of the 20 different images taken from DRIVE database.

\begin{tabular}{|c|c|c|c|c|c|c|c|c|c|}
\hline \multirow{2}{*}{ Image } & \multicolumn{3}{|c|}{ Sensitivity } & \multicolumn{3}{c|}{ Specificity } & \multicolumn{3}{c|}{ Accuracy } \\
\cline { 2 - 10 } & $\mathrm{ABC}$ & $\begin{array}{c}\text { Quick } \\
\mathrm{ABC}\end{array}$ & $\begin{array}{c}\mathrm{MR} \\
\mathrm{ABC}\end{array}$ & $\mathrm{ABC}$ & $\begin{array}{c}\text { Quick } \\
\mathrm{ABC}\end{array}$ & $\begin{array}{c}\mathrm{MR} \\
\mathrm{ABC}\end{array}$ & $\mathrm{ABC}$ & $\begin{array}{c}\text { Quick } \\
\mathrm{ABC}\end{array}$ & $\begin{array}{c}\mathrm{MR} \\
\mathrm{ABC}\end{array}$ \\
\hline 1 & 0,8913 & 0,8913 & 0,8913 & 0,9884 & 0,9884 & 0,9884 & 0,9791 & 0,9791 & 0,9791 \\
\hline 2 & 0,7857 & 0,7857 & 0,7857 & 0,9703 & 0,9703 & 0,9703 & 0,9479 & 0,9479 & 0,9479 \\
\hline 3 & 0,8787 & 0,8787 & 0,8787 & 0,9867 & 0,9867 & 0,9867 & 0,9760 & 0,9760 & 0,9760 \\
\hline 4 & 0,7230 & 0,7003 & 0,7520 & 0,9645 & 0,9605 & 0,9693 & 0,9371 & 0,9303 & 0,9454 \\
\hline 5 & 0,9514 & 0,9514 & 0,9514 & 0,9955 & 0,9955 & 0,9955 & 0,9918 & 0,9918 & 0,9918 \\
\hline 6 & 0,9572 & 0,9572 & 0,9572 & 0,9954 & 0,9954 & 0,9954 & 0,9917 & 0,9917 & 0,9917 \\
\hline 7 & 0,8874 & 0,9593 & 0,9593 & 0,9903 & 0,9967 & 0,9967 & 0,9822 & 0,9940 & 0,9940 \\
\hline 8 & 0,5506 & 0,5506 & 0,5506 & 0,9449 & 0,9449 & 0,9449 & 0,9019 & 0,9019 & 0,9019 \\
\hline 9 & 0,7818 & 0,7818 & 0,7818 & 0,9761 & 0,9761 & 0,9761 & 0,9568 & 0,9568 & 0,9568 \\
\hline 10 & 0,8932 & 0,8932 & 0,8932 & 0,9908 & 0,9908 & 0,9908 & 0,9831 & 0,9831 & 0,9831 \\
\hline 11 & 0,7870 & 0,7870 & 0,8363 & 0,9760 & 0,9760 & 0,9825 & 0,9569 & 0,9569 & 0,9685 \\
\hline 12 & 0,6624 & 0,8609 & 0,6624 & 0,9574 & 0,9861 & 0,9574 & 0,9243 & 0,9747 & 0,9243 \\
\hline 13 & 0,7407 & 0,7992 & 0,7992 & 0,9621 & 0,9725 & 0,9725 & 0,9338 & 0,9516 & 0,9516 \\
\hline 14 & 0,7439 & 0,7439 & 0,7439 & 0,9730 & 0,9730 & 0,9730 & 0,9511 & 0,9511 & 0,9511 \\
\hline 15 & 0,8966 & 0,9440 & 0,9444 & 0,9908 & 0,9953 & 0,9953 & 0,9831 & 0,9913 & 0,9913 \\
\hline 16 & 0,8387 & 0,8387 & 0,8387 & 0,9824 & 0,9824 & 0,9824 & 0,9683 & 0,9683 & 0,9683 \\
\hline 17 & 0,7017 & 0,7017 & 0,8740 & 0,9672 & 0,9672 & 0,9886 & 0,9409 & 0,9409 & 0,9971 \\
\hline 18 & 0,8972 & 0,8972 & 0,8972 & 0,9885 & 0,9885 & 0,9885 & 0,9794 & 0,9794 & 0,9794 \\
\hline 19 & 0,8161 & 0,8161 & 0,8161 & 0,9758 & 0,9758 & 0,9758 & 0,9572 & 0,9572 & 0,9572 \\
\hline 20 & 0,7477 & 0,9646 & 0,9646 & 0,9967 & 0,9963 & 0,9963 & 0,9412 & 0,9933 & 0,9933 \\
\hline Mean & $\mathbf{0 , 8 0 6 6}$ & $\mathbf{0 , 8 3 5 1}$ & $\mathbf{0 , 8 3 8 9}$ & $\mathbf{0 , 9 7 8 6}$ & $\mathbf{0 , 9 8 0 9}$ & $\mathbf{0 , 9 8 1 3}$ & $\mathbf{0 , 9 5 9 1}$ & $\mathbf{0 , 9 6 5 8}$ & $\mathbf{0 , 9 6 7 4}$ \\
\hline
\end{tabular}


Another important performance criterion for heuristic algorithms is the standard deviation which determines the stability of the algorithm. The low standard deviation indicates that the algorithm approximates similar error values at each random run. Finally, the performances of the algorithms in terms of the CPU-time which represents the elapsed time in seconds to complete all cycles have been analyzed and compared. In Table 4, minimum MSE, standard deviation and CPU-time values obtained after 20 random runs for each algorithm have been given. A bit better standard deviation value obtained for MR-ABC proves that it is a little more stable in terms of clustering when compared to $\mathrm{ABC}$ and $\mathrm{Q}-\mathrm{ABC}$ algorithms. On the other hand, from the minimum MSE values reached it can also be concluded that MR-ABC shows a bit better clustering performance than other two algorithms. The final performance metric analyzed in this section is the CPU-time. The hardware and software used in the simulations can be summarized as Intel i3 CPU with 2,13 GHz frequency, 3 GB RAM and 64 bit Windows 7 Ultimate. From CPU-time values obtained for the algorithms it is seen that MR-ABC is the slowest algorithm in terms of the time required in seconds.

Table 4. Performance comparison of $\mathrm{ABC}$, Q- $\mathrm{ABC}$ and $\mathrm{MR}-\mathrm{ABC}$ algorithms in terms of standart deviation, MSE and CPU-time values reached

\begin{tabular}{|c|c|c|c|}
\hline Method & $\begin{array}{c}\text { Minimum } \\
\text { MSE }\end{array}$ & $\begin{array}{c}\text { Standard } \\
\text { Deviation }\end{array}$ & $\begin{array}{c}\text { CPU-time } \\
\text { (Seconds) }\end{array}$ \\
\hline ABC & 0,6145 & 0,281193844 & 30,81 \\
\hline Q-ABC & 0,6417 & 0,222773107 & 30,40 \\
\hline MR-ABC & 0,4696 & 0,16412588 & 31,74 \\
\hline
\end{tabular}

In literature, there are several works [34-37] related to retinal vessel segmentation by using conventional gradient based algorithms. The statistical performances of these gradient based algorithms and $\mathrm{ABC}$ based heuristic algorithms have been compared in Table 5.

Table 5. Performance comparison of Gradient based and ABC based algorithms

\begin{tabular}{|c|c|c|c|c|}
\hline \multicolumn{2}{|c|}{ Methods } & Sensitivity & Specificity & Accuracy \\
\hline \multicolumn{2}{|c|}{ You et al. [34] } & 0,7410 & 0,9751 & 0,9434 \\
\hline \multicolumn{2}{|c|}{ Imani et al. [35] } & 0,7524 & 0,9753 & 0,9523 \\
\hline \multicolumn{2}{|c|}{ Mendonca et al. [36] } & 0,7344 & 0,9764 & 0,9452 \\
\hline \multicolumn{2}{|c|}{ Azzopardi et al. [37] } & 0,7650 & 0,9700 & 0,9440 \\
\hline \multirow{3}{*}{$\begin{array}{l}\text { Heuristic } \\
\text { algorithms }\end{array}$} & $\mathrm{ABC}$ & 0,8066 & 0,9786 & 0,9591 \\
\hline & Q-ABC & 0,8351 & 0,9809 & 0,9658 \\
\hline & MR-ABC & 0,8389 & 0,9813 & 0,9674 \\
\hline
\end{tabular}

As seen from the table, $\mathrm{ABC}$ based heuristic algorithms have better performance than the classical approaches in terms of sensitivity. Especially, Q-ABC and MR-ABC algorithms improve the sensitivity of the clustering process. Although both the gradient based and $\mathrm{ABC}$ based algorithms produce similar specificity performances, it can be 
said that $\mathrm{ABC}$ based heuristic algorithms have a bit better specificity performance. Finally, from the accuracy values obtained it can be concluded that the pixel classification performances of the $\mathrm{ABC}$ based heuristic methods are higher than or similar to the other methods in literature.

The convergence speeds obtained for the algorithms have been compared in Figure 5. As seen from the convergence figures, MR-ABC is reaching to the minimum error value at highest convergence rate. It is also seen that the $\mathrm{Q}-\mathrm{ABC}$ algorithm produces better results than the $\mathrm{ABC}$ algorithm in terms of the MSE and convergence rate. In general, it can be concluded that the convergence speeds and MSE performances of the algorithms in terms of clustering is close to each other.

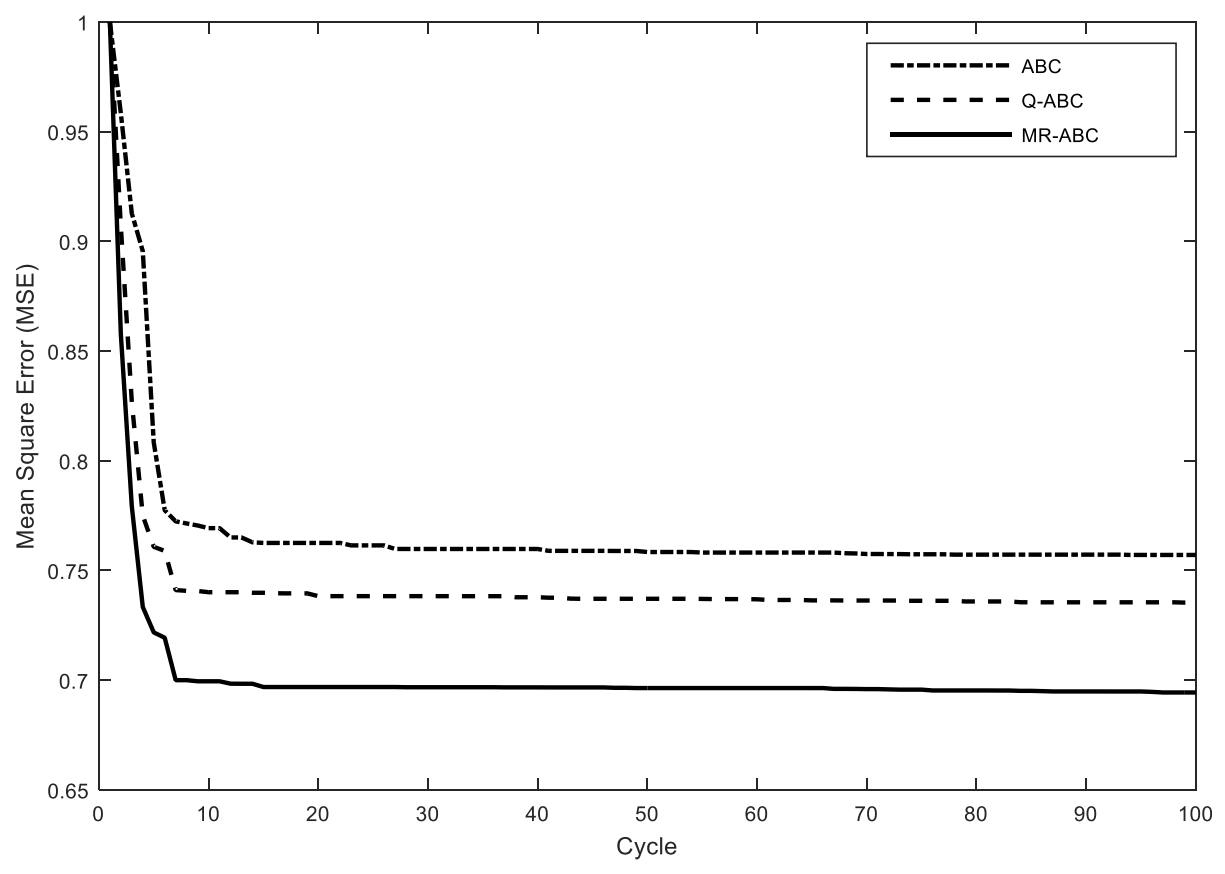

Figure 5. Performance comparison in terms of the convergence speeds

\section{Conclusion}

In this work, novel approaches based on $\mathrm{ABC}, \mathrm{Q}-\mathrm{ABC}$ and $\mathrm{MR}-\mathrm{ABC}$ algorithms for clustering based retinal vessel segmentation is described in the fundus fluorescein angiography retinal images. It is seen that the Q-ABC algorithm obtained by modifying the onlooker phase of $\mathrm{ABC}$ algorithm has a higher convergence speed and error performance than the $\mathrm{ABC}$ algorithm. Furthermore, the MR-ABC algorithm obtained by improving the process of producing neighbour solution in $\mathrm{ABC}$ algorithm has higher performance than the other two algorithms. Simulation results represent that each algorithm converges to the global solutions at similar cycles and the final MSE error values reached by the algorithms are close to each other. The statistical analyses based on the sensitivity, specificity and accuracy show that $\mathrm{ABC}, \mathrm{Q}-\mathrm{ABC}$ and MR-ABC algorithms can successfully be used in analyses of retinal images. When these statistical results are compared to that of conventional methods in literature, it is seen that ABC based approaches have similar but a bit better performance although their simple structure. On the other hand, since the standard deviation values of the MR-ABC 
algorithm are lower than $\mathrm{ABC}$ and $\mathrm{Q}-\mathrm{ABC}$ it can be concluded that MR-ABC is slightly more stable in terms of clustering based retinal vessel segmentation. As a result, $A B C$, Q-ABC and MR-ABC algorithms show similar performances in terms of clustering and they can successfully be used in retinal vessel segmentation.

\section{References}

[1] Uyen, T.V., Nguyen, A.B., Laurence, A.F.P. and Kotagiri, R., An effective retinal blood vessel segmentation method using multi-scale line detection, Pattern Recognition, 46, 3, 703-715, (2013).

[2] Shuangling, W., Yilong, Y., Guibao, C., Benzheng, W., Yuanjie, Z. and Gongping, Y., Hierarchical retinal blood vessel segmentation based on feature and ensemble learning, Neurocomputing, 149, Part B, 708-717, (2015).

[3] Soares, J.V.B., Leandro, J.J.G., Cesar, J.R.M., Jelinek, H.F. and Cree, M.J., Retinal vessel segmentation using the 2-D Gabor wavelet and supervised classification, IEEE Medical Imaging, 25, 9, 1214-1222, (2006).

[4] Frame, A.J., Undrill, P.E., Cree, M.J., Olson, J.A., McHardy, K.C., Sharp, P.F., et al., A comparison of computer based classification methods applied to the detection of microaneurysms in ophthalmic fluorescein angiograms, Computers in Biology and Medicine, 28, 3, 225-238, (1998).

[5] Larsen, M., Godt, J., Larsen, N., Lund-Andersen, H., Sjølie, A.K., Agardh, E., et al., Automated detection of fundus photographic red lesions in diabetic retinopathy, Invest Ophthalmol Visual Science, 44, 2, 761-766, (2003).

[6] Zana, F. and Klein, J.C., Segmentation of vessel-like patterns using mathematical morphology and curvature evaluation, IEEE Transaction on Image Processing, 10, 7, 1010-1019, (2001).

[7] Jiang, X. and Mojon, D., Adaptive local thresholding by verification based multi threshold probing with application to vessel detection in retinal images, IEEE Transactions on Pattern Analysis and Machine Intelligence, 25, 1, 131-137, (2003).

[8] Mendonca, A.M. and Campilho, A., Segmentation of retinal blood vessels by combining the detection of centerlines and morphological reconstruction, IEEE Transactions on Medical Imaging, 25, 9, 1200-1213, (2006).

[9] Chaudhuri, S., Chatterjee, S., Katz, N., Nelson, M. and Goldbaum, M., Detection of blood vessels in retinal images using two-dimensional matched filters, IEEE Transactions on Medical Imaging, 8, 3, 263-269, (1989).

[10] Hoover, A., Kouznetsova, V. and Goldbaum, M., Locating blood vessels in retinal images by piecewise threshold probing of a matched filter response, IEEE Transactions on Medical Imaging, 19, 3, 203-210, (2000).

[11] Ng, J., Clay, S.T., Barman, S.A., Fielder, A.R., Moseley, M.J., Parker, K.H. and Paterson, C., Maximum likelihood estimation of vessel parameters from scale space analysis, Image and Vision Computing, 28, 1, 55-63, (2010).

[12] Zhang, B., Zhang, L. and Karray, F., Retinal vessel extraction by matched filter with first-order derivative of Gaussian, Computers in Biology and Medicine, 40, 4, 438-445, (2010).

[13] Narasimha-Iyer, H., Mahadevan, V., Beach, J.M. and Roysam, B., Improved detection of the central reflex in retinal vessels using a generalized dualGaussian model and robust hypothesis testing, IEEE Transactions on Information Technology in Biomedicine, 12, 3, 406-410, (2008). 
[14] Bankhead, P., Scholfield, C.N., McGeown, J.G. and Curties, T.M., Fast retinal vessel detection and measurement using wavelets and edge location refinement, PLoS One, 7, 3, e32435, (2012).

[15] Zhou, L., Rzeszotarsk, M.S., Singerman, L.J. and Chokreff, J.M., The detection and quantification of retinopathy using digital angiograms, IEEE Transactions on Medical Imaging, 13, 4, 619-626, (1994).

[16] Delibasis, K.K., Kechriniotis, A.I., Tsonos, C. and Assimakis, N., Automatic model based tracing algorithm for vessel segmentation and diameter estimation, Computational Methods and Programs in Biomedicine, 100, 2, 108-122, (2010).

[17] Adel, M., Moussaoui, A., Rasigni, M., Bourennane, S. and Hamami, L., Statistical-based tracking technique for linear structures detection: application to vessel segmentation in medical images, IEEE Signal Processing Letters, 17, 6, 555-558, (2010).

[18] Vlachos, M. and Dermatas, E., Multi-scale retinal vessel segmentation using line tracking, Computerized Medical Imaging and Graphics, 34, 3, 213-227, (2010).

[19] Perfetti, R., Ricci, E., Casali, D. and Costantini, G., Cellular neural networks with virtual template expansion for retinal vessel segmentation, IEEE Transactions on Circuits and Systems II, 54, 2, 141-145, (2007).

[20] Fathi, A. and Naghsh-Nilchi, A.R., General rotation-invariant local binary patterns operator with application to blood vessel detection in retinal images, Pattern Analysis and Applications, 17, 1, 69-81, (2014).

[21] Marín, D., Aquino, A., Gegúndez-Arias, M.E. and Bravo, J.M., A new supervised method for blood vessel segmentation in retinal images by using gray-level and moment invariants-based features, IEEE Transactions on Medical Imaging, 30, 1, 146-158, (2011).

[22] Staal, J.J., Abramoff, M.D., Niemeijer, M., Viergever, M.A. and VanGinneken, B., Ridge based vessel segmentation in color images of the retina, IEEE Transactions on Medical Imaging, 23, 4, 501-509, (2004).

[23] Ricci, E. and Perfetti, R., Retinal blood vessel segmentation using line operators and support vector classification, IEEE Transactions on Medical Imaging, 26, 10, 1357-1365, (2007).

[24] You, X., Peng, Q., Yaun, Y., Cheng, Y. and Lei, J., Segmentation of retinal blood vessels using the radial projection and semi-supervised approach, Pattern Recognition, 44, (11-10), 2314-2324, (2011).

[25] Garg, S., Sivaswamy, J. and Chandra, S., Unsupervised curvature-based retinal vessel segmentation, Proceedings of the IEEE International Symposium on Bio-Medical Imaging: From Nano to Macro, 344-347, Hyderabad, (2007).

[26] Palomera-Perez, M.A., Martinez-Perez, M.E., Benitez-Perez, H. and OrtegaArjona, J.L, Parallel multiscale feature extraction and region growing: application in retinal blood vessel detection, IEEE Transactions on Information Technology in Biomedicine, 14, 2, 500-506, (2010).

[27] Martinez-Perez, M.E., Hughes, A.D., Thom, S.A., Bharath, A.A. and Parker, K.H., Segmentation of blood vessels from red-free and fluorescein retinal images, Medical Image Analysis, 11, 1, 47-61, (2007).

[28] Xu, X., Niemeijer, M., Song, Q., Sonka, M., Garvin, M.K., Reinhardt, J.M., et al., Vessel boundary delineation on fundus images using graph based approach, IEEE Transactions on Medical Imaging, 30, 6, 1184-1191, (2011). 
[29] Walter, T., Massin, P., Erginay, A., Ordonez, R., Jeulin, C. and Klein, J.C., Automatic detection of microaneurysms in color fundus images, Medical Image Analysis, 11, 6, 555-566, (2007).

[30] Hassanien, A.E., Emary, E. and Zawbaa, H.M., Retinal blood vessel localization approach based on bee colony swarm optimization, fuzzy c-means and pattern search, Journal of Visual Communication and Image Representation, 31, 186-196, (2015).

[31] Karaboga, D., An idea based on honey bee swar for numerical optimization, Technical Report-TR06, Erciyes University, Engineering Faculty, Computer Engineering Department, Kayseri, (2005).

[32] Karaboga, D. and Gorkemli, B., A quick artificial bee colony (qABC) algorithm and its performance on optimization problems, Applied Soft Computing, 23, 227-238, (2014).

[33] Karaboga, D. and Basturk, B., Artificial bee colony (ABC) optimization algorithm for solving constrained optimization problems, LNCS: Advances in Soft Computing: Foundations of Fuzzy Logic and Soft Computing, 4529,789-798, (2007).

[34] You X, Peng Q, Yaun Y, Cheng Y, Lei J. Segmentation of retinal blood vessels using the radial projection and semi-supervised approach, Pattern Recognition, 44, 10, 2314-2324, (2011).

[35] Imani E, Javidi M, Pourreza HR. Improvement of retinal blood vessel detection using morphological component analysis, Computer Methods and Programs in Biomed, 118, 3, 263-279, (2015).

[36] Mendonca AM, Campilho A. Segmentation of retinal blood vessels by combining the detection of centerlines and morphological reconstruction, IEEE Transactions on Medical Imaging, 25, 9, 1200-1213, (2006).

[37] Azzopardi G, Strisciuglio N, Vento M, Petkov N. Trainable COSFIRE filters for vessel delineation with application to retinal images, Medical Image Analysis, 19, 1, 46-57, (2015). 